\title{
Research Paper: Comparing the Effects of Emotion-focused Couple Therapy and Acceptance and Commitment Therapy on Marital Conflict and Emotion Regulation
}

\author{
Shahrbanoo Ghahari ${ }^{1}$ (D), Leili Jamil ${ }^{2 *}$ (D), Nazanin Farrokhi ${ }^{3}$, Reza Davoodi ${ }^{4}$ \\ 1. Department of Mental Health, School of Behavioral Sciences and Mental Health (Tehran Institute of Psychiatry), Iran University of Medical Sciences, \\ Tehran, Iran. \\ 2. Department of Clinical Psychology, AJA University of Medical Sciences, Tehran, Iran. \\ 3. Department of Clinical Psychology, School of Psychology, Roudehen Branch, Islamic Azad University, Roudehen, Iran. \\ 4. Department of Clinical Psychology, School of Psychology, Tonekabon Branch, Islamic Azad University, Tonekabon, Iran.
}

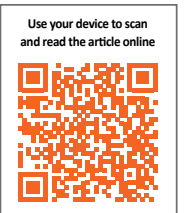

Cetteation: Ghahari, S., Jamil, L., Farrokhi R., Davoodi, R. (2020). Comparing the Effects of Emotion-focused Couple Therapy and Acceptance and Commitment Therapy on Marital Conflict and Emotion Regulation. Journal of Practice in Clinical Psychology, 9(2), 121-132. https://doi.org/10.32598/jpcp.9.2.718.1

dol https://doi.org/10.32598/jpcp.9.2.718.1

\section{(1) (3)}

Article info:

Received: 12 Oct 2020

Accepted: 25 Jan 2021

Available Online: 01 Apr 2021

Keywords:

Emotion-Focused Therapy, Acceptance and Commitment Therapy, Emotion regulation, Marital conflict

\section{ABSTRACT}

Objective: Marital conflict can be described as the state of tension or stress between couples. Accordingly, couples who are unable to regulate their negative emotions experience fragile relationships. This study aimed to compare the effects of Emotion-Focused Couple Therapy (EFCT) and Acceptance and Commitment Therapy (ACT) on Cognitive Emotion Regulation (CER) strategies and marital conflict.

Methods: The study sample included 28 married women who were randomly assigned to the EFCT and ACT groups. The questionnaire battery included the Questionnaire of Marital Conflicts, the Cognitive Emotion Regulation Questionnaire, and the Second Edition of the Structured Clinical Interview for the Diagnostic and Statistical Manual of Mental Disorders (DSM) (SCID-II).

Results: The result of the Independent Samples t-test indicated no difference in pretest scores of the study participants. However, significant differences were determined between the study groups in the posttest phase $(\mathrm{P}<0.001)$. Additionally, the Paired Samples t-test results revealed significant differences between pretest and posttest scores between the EFCT $(\mathrm{P}<0.001)$ and ACT ( $\mathrm{P}<0.028$ for marital conflict, $\mathrm{P}<0.001$ for adaptive CER strategies, $\& \mathrm{P}<0.031$ for nonadaptive CER strategies) groups. Moreover, EFCT was clinically more effective than ACT. Accordingly, the effect size of EFCT and ACT for marital conflict was measured as 2.33 and 0.83 ; respecting adaptive and non-adaptive CER strategies, these values were computed as 2.89 and 2.02 as well as 2.89 and 0.88 , respectively.

Conclusion: Overall, EFCT and ACTT were effective in improving marital conflict and CER strategies. Besides, EFCT was clinically more effective than ACT in this regard.

* Corresponding Author:

Leili Jamil, Phd.

Address: Department of Clinical Psychology, AJA University of Medical Sciences, Tehran, Iran.

Tel: +98 (21) 86096350

E-mail: l.jamil@ajaums.ac.ir 


\section{Highlights}

- Marital conflict is among the most stressful situations individuals encounter.

- Emotion regulation plays a critical role in interpersonal outcomes, such as couples' relationship quality and conflict management.

- EFCT and ACTT are effective in improving marital conflict and cognitive emotion regulation strategies. Besides, EFCT is clinically more effective than ACT in this respect.

\section{Plain Language Summary}

The issue of conflicts in married life is natural and profoundly prevalent in couples. Almost all couples who marry state a high level of marital satisfaction at the beginning. Marital conflict is a critical risk factor for biopsychological problems. Fortunately, recent research determined that emotion regulation plays a central role in couples' relationship quality. Therefore, this study aimed to compare the effects of two common treatment methods on emotion regulation strategies and marital conflict, namely Emotion-Focused Couple Therapy (EFCT) and Acceptance and Commitment Therapy (ACT). The collected results suggested that both treatment approaches were effective in improving marital conflict and emotion regulation strategies in couples; however, EFCT was clinically more effective than ACT in this area.

\section{Introduction}

ommunication, as a fundamental characteristic of all intimate relationships, makes the mismatch to be inevitable and extremely obvious. The issue of conflicts in married life is natural and profoundly prevalent in couples. Almost all couples who marry state a high level of marital satisfaction at the beginning; however, relationship satisfaction gradually diminishes (Kiecolt-Glaser, Bane, Glaser \& Malarkey, 2003; Markman \& Hahlweg, 1993; Markman, Rhoades, Stanley, Ragan \& Whitton, 2010). Marital conflict and divorce are among the most stressful situations individuals encounter. Marital conflict can be described as the state of tension or stress between couples while they attempt to accomplish their marital roles (Tolorunleke, 2014). In other words, marital conflict is supposed as the interaction between spouses who have incompatible affairs, viewpoints, and opinions (Strong et al., 2011).

The impacts of marital conflict affect numerous familial aspects (Braithwaite, Delevi \& Fincham, 2010). Moreover, research studies revealed that conflict and distress are critical risk factors for biopsychological problems. Partners in distressed relationships are more prone to experience anxiety, depression, suicidality, substance abuse, as well as acute and chronic medical conditions (Gurman, Lebow \& Snyder, 2015; Hahlweg \& Richter, 2010; Litzinger \& Gordon, 2005; Miller, Hollist, Olsen
\& Law, 2013). Furthermore, studies on couples' physical health indicated that marital conflict is usually accompanied by a more vulnerable immune system function in both spouses. Marital distress in couples presents direct adverse influences on cardiovascular, endocrine, nervous, sensory, and other physiological systems (Snyder, Castellani \& Whisman, 2006). Additionally, marital destructive interaction results in decreased sexual satisfaction enhanced conflicts, and greater odds of divorce (Amato \& Hohmann-Marriott, 2007; Birditt, Brown, Orbuch \& McIlvane, 2010; Birditt, Wan, Orbuch \& Antonucci, 2017; Lindahl \& Malik, 2011).

Additionally, scholars determined that Emotion Regulation (ER) plays a critical role in interpersonal outcomes, such as couples' relationship quality and conflict management (John \& Gross, 2004; Qadar, 2016). Individuals employ various strategies to regulate their emotions. Accordingly, Cognitive Emotion Regulation Strategies (CERS) pertain to what individuals consciously consider to manage their emotions in response to evoking situations and adverse events (Balzarotti, Biassoni, Villani, Prunas \& Velotti, 2016; Gross, 2001). CERS can be adaptive (e.g. positive reframing \& reappraisal) or maladaptive (emotion suppression or rumination) (Aldao \& Nolen-Hoeksema, 2012). For instance, reappraisal is associated with positive relationship consequences, like marital quality (Finkel, Slotter, Luchies, Walton \& Gross, 2013); however, suppression is correlated with negative interpersonal behaviors (Vater \& SchröderAbé, 2015). 
Generally, an effective ER can improve emotional harmony, foster interpersonal coherence, and result in higher marital satisfaction (Gottman, 2014; Levenson, Haase, Bloch, Holley \& Seider, 2013). However, less effective ERSs are associated with aggravated harmful relationship conflicts (Curşeu, Boroş \& Oerlemans, 2012). Therefore, one vital developmental milestone is the capability to use strategies that regulate fractious emotions (McRae, 2016). Researchers proposed that partners' ER problems were connected with hostile criticism (Klein, Renshaw \& Curby, 2016), decreased relationship satisfaction (Bloch, Haase \& Levenson, 2014), an elevated risk of relational violence (McNulty \& Hellmuth, 2008), and high risks of cardiovascular conditions for both spouses through conflictual interactions (Ben-Naim, Hirschberger, Ein-Dor \& Mikulincer, 2013). Couples who are unable to regulate negative emotions and focus on their anger and hatred subsequent stressful events experience fragile relationships (Herzberg, 2013).

Consequently, there exist some general reasons why spouses seek or are referred for consulting. Such reasons usually include relational issues, such as emotional withdrawal and declined commitment, authority struggles, value and role conflicts, problem-solving and interactional challenges, extramarital relationships, sexual dissatisfaction, and violence (Geiss \& Daniel O'Leary, 1981; Whisman, Dixon \& Johnson, 1997). In general, spouses seek therapy due to perils to the safety and balance of their relationships with the most significant attachment figures of adult life (Gurman et al., 2015; Johnson \& Denton, 2002). A helpful treatment approach is Emotion-Focused Couple Therapy (EFCT). EFCT is developed based on the attachment theory; it makes up an experiential focus on emotional experience with stress on how insecure emotional attachment can cause cyclical interactions (Johnson, Hunsley, Greenberg \& Schindler, 1999). In this view, marital conflict is assumed as the negative loop of communication patterns. Such patterns arise from the pain and despair that emerge when the adult needs for attachment, being accepted and validated are failed to meet (Girard \& Woolley, 2017; Greenberg \& Goldman, 2007; Woldarsky Meneses, 2017).

EFCT intends to modify problematic loops. This is achieved by aiding partners to explore and display their underlying fundamental emotions that may provide new and corrective emotional experiences (Greenberg \& Johnson, 1988). Specifically, EFCT recognizes the emotions; subsequently, it interprets them into understandable and adaptive messages and behaviors. Thus, failure to transfer the affective conditions may lead to conflicts in interpersonal relationships (Girard \& Woolley, 2017;
Greenman \& Johnson, 2013). The effectiveness of EFCT was evaluated in prior studies such as Solymani Ahmadi, Zarei \& Fallahchai (2014), Soleimani et al. (2015), and Rostami and associates (2014). The results of these studies indicated that ECFT significantly decreased marital conflict, and significantly enhanced satisfaction, cohesion, and affectional expression. EFCT impacted physical and emotional-sexual satisfaction among infertile couples. Despite numerous research concerning the effects of EFCT on Cognitive Emotion Regulation Strategies (CERS) in various populations, research on the effects of EFCT on CERS in couples with marital conflict remains scarce.

Acceptance and Commitment Therapy (ACT) is the other approach with extensive literature respecting its effects on marital conflict (Ahmadzadeh, Vaezi, Sodagar \& Golmohammad Nazhad, 2019; Amani, Isanejad \& Alipour, 2018; Arabnejad et al., 2014; Peterson, Eifert, Feingold \& Davidson, 2009). According to ACT, marital conflict develops through each spouse's inflexible and unpractical experiential avoidance strategies in the context of couple relationships, such as avoiding expressing emotional or physical intimacy due to the fear of rejection. These experiential avoidance strategies may process temporary relief; occasionally, these approaches may prevent undergoing unpleasant thoughts and emotions. However, they ultimately cause more distress, pain, and relational disturbance (Peterson et al., 2009). Therefore, the objective of ACT is to make the spouses mindful of their own and their partner's cognitive and emotional responses/actions. ACT also modifies psychological inflexibility in individuals. Such a goal is achieved by applying 6 central processes, namely acceptance, projection, one-self as the field, relationship with the present time, clarifying values, and committed action (Hayes \& Strosahl, 2013; Peterson et al., 2009).

On account of ACT investigations, these processes enhance psychological flexibility. In turn, it increases the satisfaction and quality of the marital life, also decreases marital conflicts with a constant impact (Arabnejad et al., 2014; Khanjani Veshki, Shafiabady, Farzad \& Fatehizade, 2016). The effects of ACT were evaluated in studies, such as Khanjani Veshki et al. (2016), Kavousian, Haniffi \& Karimi (2017), as well as Khanei, Jazayeri, Bahrami, Montazeri \& Etemadi (2018). These studies revealed that ACT significantly decreased marital conflict and enhanced marital satisfaction. However, research respecting the effects of ACT on CERS in couples with marital conflict remains scarce. 
Generally, no experimental evidence exists for evaluating the effects of EFCT and ACT on CERS in couples with marital conflict. Despite the relatively extensive research on the effects of couple therapies, scholars overlooked comparing the effects of EFCT and ACT on marital conflict and CERS in couples. Therefore, the main purpose of the present study was to compare the effects of EFCT and ACT on marital conflict and CERS. Studies highlighted that men and women played different roles in the relationship. Accordingly, women tend to attack more often than men; however, men tend to compromise more frequently. Furthermore, women are more prone to engage in conflicts and tend to evaluate relationships more critically than men. Besides, women may seek to modify marital interaction more actively and recurrently; as a result, they seek treatment for conflict resolution with a more probability than men (Delatorre \& Wagner, 2018). Accordingly, this study aimed to only recruit women. Finally, the current study hypothesized that the effectiveness of EFCT is more than that of ACT on marital conflict and CERS.

\section{Materials and Methods}

This was a randomized controlled trial with two treatment groups (ACT \& EFCT). In total, 30 married women participated in this study; however, only 28 subjects completed the treatment process (the samples dropped out in the first \& second sessions). The necessary sample was selected among all married women with marital conflict referring to the Clinic of Tehran Psychiatric Institute for Couple Therapy. The study samples were selected by the convenience sampling method. Furthermore, the inclusion criteria of the study were the age range of 20-50 years, a minimum diploma certificate, as well as having marital conflict and problems. The exclusion criteria were participating in any concurrent psychological treatment, substance abuse problems, a diagnosis of personality disorders, and absence from $>2$ treatment sessions.

The relevant ethical approval was acquired from the Ethics Committee for Research at Mazandaran University of Medical Sciences (code: IR.MAZUMS. REC.1396.2695). After recruiting the study samples, an evaluation session was held to assess the inclusion and exclusion criteria, i.e., performed by the corresponding author. For this purpose, the absence of personality disorders was checked using the Second Edition of the Structured Clinical Interview for the Diagnostic and Statistical Manual of Mental Disorders (DSM) (SCID-II) interview; the absence of substance abuse problems was assessed by probing drug use/abuse history. Eventually, the required explanations were provided to the study subjects about the process of treatment. Consequently, they voluntarily provided the informed consent form to participate in this research.

Next, the study participants were randomly assigned to the ACT and EFCT groups. All study participants completed the research questionnaires before the treatment (pretest). Additionally, at the end of the intervention phase, they were invited to re-complete the questionnaires (posttest). The EFCT was conducted based on the instructions of Johnson et al. (1999) and performed by the first author. Moreover, ACT was designed according to the instructions of Peterson et al. (2009) and performed by the third author. ACT and EFCT were performed in eight 90-min face-to-face individual sessions.

The questionnaire battery included demographic characteristics form (age \& academic level), the Marital Conflict Questionnaire, the Cognitive Emotion Regulation Questionnaire, and the SCID-II.

\section{Marital Conflict Questionnaire (MCQ)}

MCQ is a 42-item scale assessing marital conflict in couples, designed by Barati and Sanai, in 1996. This tool has 7 subscales, including reduced cooperation; reduced sexual intercourse; increased emotional reactions; child support; personal relationships with relatives; reduced family relationships with the spouse's relatives, and separating finances. Each item is rated on a scale of 1 to 5 . This questionnaire categorizes couples' conflict at 4 levels, as follows: non-conflict (ranged from 42 to 74), normal conflict (ranged from 75 to 114), conflict higher than normal (ranged from 115 to134) and escalated conflict (ranged from135 to 210). The designers of the questionnaire reported good reliability of MCQ using Cronbach's alpha coefficient $(0.73)$

\section{Cognitive Emotion Regulation Questionnaire- Short}

The CERQ-S was developed in 1999 to assess the particular CERS that individuals apply in response to threatening or stressful life events. It has 18 items and 9 subscales, consisting of self-blame; other-blame; rumination; catastrophizing; putting into perspective; positive refocusing; positive reappraisal; acceptance, and planning. Each item is rated on a scale of 1(never) to 5(always). A higher score indicates greater use of CER. The psychometric properties of the CERQ have been signified to be good, with Cronbach's alpha coefficients over 0.70 in most studies (Garnefski, Baan \& Kraaij, 2005; Garnefski \& Kraaij, 2006). The reliability of the Persian 
version of the CERQ-S was found as 0.76-0.92 using Cronbach's alpha coefficient approach (Hasani, 2011).

\section{Structured Clinical Interview for DSM-IV Disor- ders-2 (SCID-II)}

SCID-II is a semi-structured interview, used to diagnose common axis II disorders according to the DSM-IV criteria. SCID-II contains 10 personality disorder criteria. The inter-rater reliability coefficients of this tool ranged from 0.48 to 0.98 for categorical diagnosis, as well as from 0.90 to 0.98 for the intraclass correlation coefficient. The internal consistency coefficients of SCID-II were adequate, from 0.71 to 0.94 (Maffei et al., 1997). The content validity of the Persian version of SCID-II was confirmed. Besides, the reliability coefficient of this test was obtained using the test-retest method within one week, i.e., 0.87 .

All analyses were conducted using SPSS. First, descriptive statistics were used for the subjects' demographic data. For evaluating the normal distribution of the data, Kolmogorov Smirnov was performed. The Independent Samples t-test was conducted to compare the differences between the study groups. Furthermore, the Paired Samples t-test was calculated for assessing the difference between the pretest and posttest data. Moreover, the effect size of each sample was estimated. The significance level was set at $\mathrm{P}<0.05$ for all statistics.

\section{Results}

The collected demographic characteristics demonstrated that most of the subjects in the EFCT group aged
26-30 years, i.e., approximately $28.6 \%$. Moreover, most of the ACT group's sample aged 31-35 years, i.e., about $17.9 \%$. Most of the ACT and EFCT groups subjects' educational level was BA and diploma and BA, respectively (Table 1).

As per Table 2, the obtained data were normally distributed in all study variables; thus, the Independent Samples t-test was performed.

The Independent Samples t-test data indicated no difference in the pretest scores of the study subjects. Besides, significant differences were detected between the study groups in the posttest scores (Table 3 ).

According to Table 4, significant differences were found between pretest and posttest data of the intervention groups. In other words, the relevant results demonstrated that both provided couple therapies were effective in improving marital conflict and CERS among the research sample. Regarding Cohen's d, the effects of both interventions were clinically significant on marital conflict and CERS in the study participants. Moreover, based on Cohen's d and $r$ rates, EFCT was clinically more effective than ACT on marital conflict and CERS in the study subjects.

\section{Discussion}

The present study compared the effects of EFCT and ACT on CERS and marital conflict in females. The obtained results supported the effectiveness of EFCT and ACT on the marital conflict in the study subjects. The collected findings were consistent with those of Sham-

Table 1. The group-wise characteristics of the study subjects

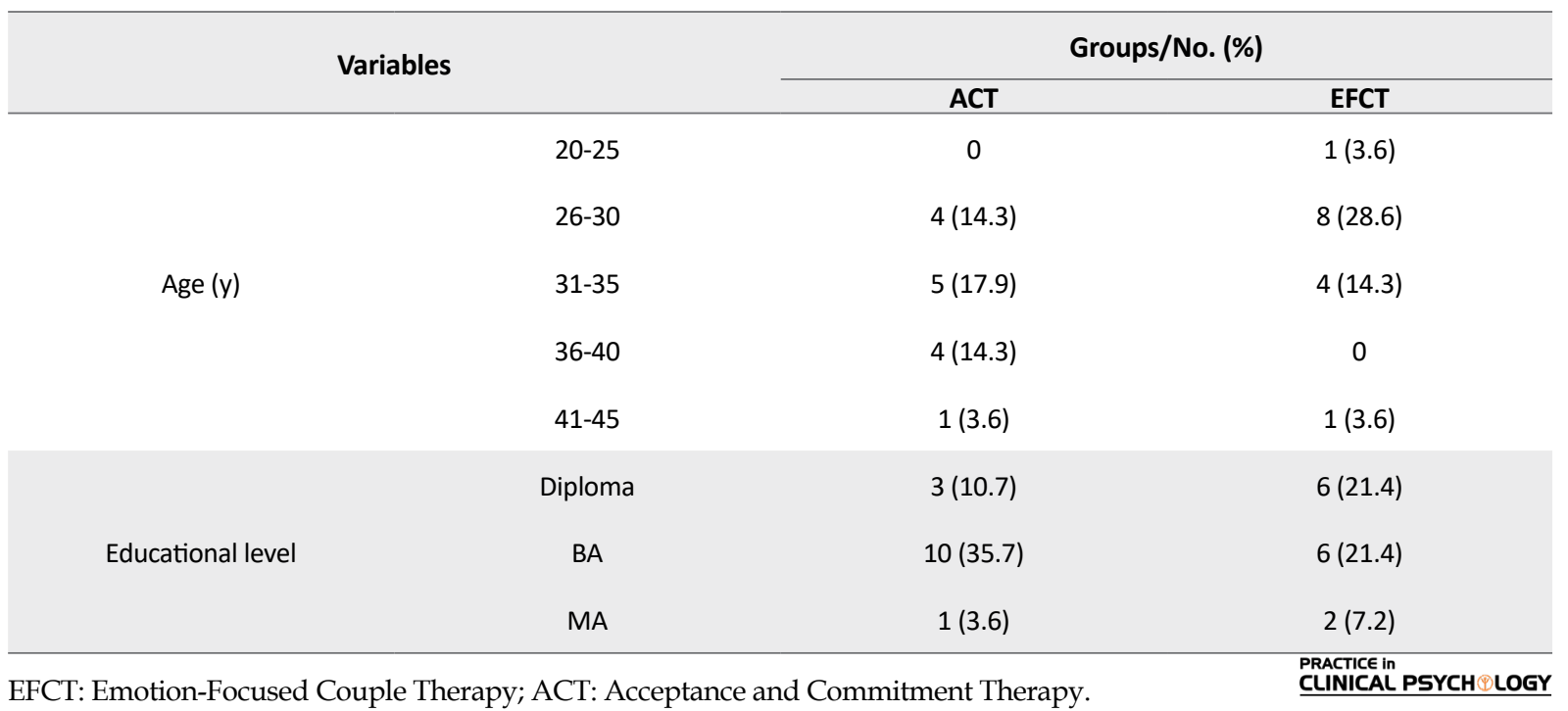


Table 2. Descriptive indices and Kolmogorov-Smirnov test data in the research groups

\begin{tabular}{|c|c|c|c|c|c|c|c|c|}
\hline \multirow{2}{*}{ Variables } & \multirow{2}{*}{\multicolumn{2}{|c|}{ Groups }} & \multicolumn{3}{|c|}{ Pretest } & \multicolumn{3}{|c|}{ Posttest } \\
\hline & & & Mean \pm SD & KS & $\mathbf{P}$ & Mean士SD & KS & $\mathbf{P}$ \\
\hline \multirow{2}{*}{$\begin{array}{l}\text { Marital } \\
\text { conflict }\end{array}$} & \multicolumn{2}{|c|}{ EFCT } & $127.79 \pm 17.33$ & 0.17 & 0.200 & $97.86 \pm 5.39$ & 0.22 & 0.069 \\
\hline & \multicolumn{2}{|c|}{ ACT } & $130.45 \pm 8.28$ & 0.17 & 0.200 & $137.07 \pm 7.63$ & 0.19 & 0.147 \\
\hline \multirow{5}{*}{ CERS } & \multirow{3}{*}{ Adaptive } & EFCT & $27.43 \pm 4.16$ & 0.19 & 0.144 & $39.36 \pm 4.09$ & 0.15 & 0.200 \\
\hline & & ACT & $26.50 \pm 3.59$ & 0.16 & 0.200 & $33.59 \pm 3.41$ & 0.12 & 0.200 \\
\hline & & & & & & & & \\
\hline & \multirow{2}{*}{$\begin{array}{c}\text { Non- } \\
\text { Adaptive }\end{array}$} & EFCT & $22.64 \pm 3.15$ & 0.17 & 0.200 & $32.29 \pm 3.52$ & 0.18 & 0.200 \\
\hline & & ACT & $23.50 \pm 2.35$ & 0.21 & 0.063 & $26.0 \pm 3.26$ & 0.19 & 0.172 \\
\hline
\end{tabular}

EFCT: Emotion-focused Couple Therapy, ACT: Acceptance and Commitment Therapy; CERS: cognitive emotion regulation strategies

sipour, Norouzi Kouhdasht, Mohammadi, Azari \& Norouzi (2018), Havaasi, Zahra Kaar \& Mohsen Zadeh (2018), Naghdi Hatami, Kayamanesh \& Navobinejad (2017), Beasley \& Ager (2019), Najafi, Soleimani, Ahmadi, Javidi \& Hoseini Kamkar (2015), Solymani Ahmadi et al. (2014), Priest (2013), Khanjani Veshki et al. (2016), Amani et al. (2018), as well as Farahanifar, Heidari, Davodi \& Aleyasin (2019).

Furthermore, the present research results revealed that EFCT was more effective than ACT on marital conflict; these data may be explained based on some assumptions of EFCT regarding the origins of couples' conflicts. Marital conflict and relationship distress are viewed as emerging from spouses being unable to fulfill each other's needs. Besides, EFCT helps spouses to become informed of their needs, express them, and become sensitive and responsive to their spouses' needs (Vanhee, Lemmens, Moors, Hinnekens \& Verhofstadt, 2018). Furthermore, the need for attachment is central in the understanding of couple distress; insecure attachment to the spouse has been generally correlated with relationship dysfunctioning, including decreased relationship satisfaction, commitment, and intimacy, as well as aggravated conflicts and less stable relationships (Kirkpatrick \& Davis, 1994; Mikulincer \& Shaver, 2010; Treboux, Crowell \& Waters, 2004). Consequently, EFCT assists couples to develop a secure attachment bond by expressing the vulnerabilities, i.e., soothed in an emotionally harmonized manner and forming mutual emotional approachability and responsiveness (Wiebe \& Johnson, 2016). However, from ACT's perspective,

Table 3. Independent samples t-test results for the research variables

\begin{tabular}{|c|c|c|c|c|c|c|c|c|}
\hline \multirow{2}{*}{ Variables } & \multirow{2}{*}{\multicolumn{2}{|c|}{ Groups }} & \multicolumn{3}{|c|}{ Pretest } & \multicolumn{3}{|c|}{ Posttest } \\
\hline & & & Mean \pm SD & $\mathbf{t}$ & $\mathbf{P}$ & Mean $\pm S D$ & $\mathbf{t}$ & $\mathbf{P}$ \\
\hline \multirow{2}{*}{$\begin{array}{l}\text { Marital } \\
\text { conflict }\end{array}$} & \multicolumn{2}{|c|}{ EFCT } & $127.78 \pm 17.33$ & & & $97.86 \pm 5.39$ & & \\
\hline & \multicolumn{2}{|c|}{ ACT } & $130.44 \pm 8.27$ & -0.32 & 0.000 & $137.07 \pm 7.63$ & -15.10 & 0.001 \\
\hline \multirow{6}{*}{ CERS } & \multirow{3}{*}{ Adaptive } & EFCT & $27.42 \pm 4.16$ & \multirow{3}{*}{0.63} & \multirow{3}{*}{0.533} & $39.36 \pm 4.09$ & \multirow{3}{*}{4.05} & \multirow{3}{*}{0.001} \\
\hline & & & & & & & & \\
\hline & & ACT & $26.5 \pm 3.6$ & & & $33.59 \pm 3.41$ & & \\
\hline & & & & & & & & \\
\hline & \multirow{2}{*}{$\begin{array}{c}\text { Non- } \\
\text { Adaptive }\end{array}$} & EFCT & $22.64 \pm 3.15$ & \multirow[b]{2}{*}{-0.81} & \multirow[b]{2}{*}{0.422} & $32.29 \pm 3.52$ & \multirow[b]{2}{*}{4.90} & \multirow[b]{2}{*}{0.001} \\
\hline & & & $23.5 \pm 2.34$ & & & & & \\
\hline
\end{tabular}

EFCT: Emotion-Focused Couple Therapy; ACT: Acceptance and Commitment Therapy; CERS: cognitive emotion regulation strategies. 
Table 4. Paired samples t-test and effect size of pretest and posttest scales for the research variables

\begin{tabular}{|c|c|c|c|c|c|c|c|}
\hline \multirow{2}{*}{ Variables } & \multirow{2}{*}{\multicolumn{2}{|c|}{ Groups }} & Pair Differences & \multirow{2}{*}{$t$} & \multirow{2}{*}{$\mathbf{P}$} & \multirow{2}{*}{ Cohen's d } & \multirow{2}{*}{$r$} \\
\hline & & & Mean $\pm S D$ & & & & \\
\hline \multirow{2}{*}{ Marital conflic } & \multicolumn{2}{|c|}{ EFCT } & $29.93 \pm 15.68$ & 7.17 & 0.001 & 2.33 & 0.76 \\
\hline & \multicolumn{2}{|c|}{ ACT } & $-6.62 \pm 10.02$ & -2.47 & 0.028 & -0.83 & -0.38 \\
\hline \multirow{5}{*}{ CERS } & \multirow{3}{*}{ Adaptive } & EFCT & $-11.92 \pm 6.36$ & -7.01 & 0.001 & -2.89 & -0.82 \\
\hline & & ACT & $-7.08 \pm 5.37$ & -4.93 & 0.001 & -2.02 & -0.71 \\
\hline & & & & & & & \\
\hline & \multirow{2}{*}{$\begin{array}{l}\text { Non- Adap- } \\
\text { tive }\end{array}$} & EFCT & $-9.64 \pm 4.61$ & -7.81 & 0.001 & -2.89 & -0.82 \\
\hline & & ACT & $-2.50 \pm 3.86$ & -2.42 & 0.031 & -0.88 & -0.40 \\
\hline
\end{tabular}

EFCT: Emotion-Focused Couple Therapy; ACT: Acceptance and Commitment Therapy; CERS: cognitive emotion regulation strategies.

distress and conflicts in couples originate from each partner's inflexible and impracticable experiential avoidance strategies. Additionally, there exists fusion with thoughts and feelings about the actions or lack of actions in the relationship. Furthermore, accepting such thoughts as real and acting on them preserves spouses' negative relationship loops. Therefore, ACT attempts to minimize such thinking processes; thus, it decreases pain in couples induced by each partner's experiential avoidances. ACT helps spouses become mindful of their cognitive and emotional responses within the relationship. Moreover, it facilitates purifying the values of couples in their relationship and supports harmoniously acting with these values (Peterson et al., 2009). Substantially, EFCT helps couples to recognize, experience, and communicate clear and poignant emotional necessities. These profound emotional experiences commonly unfold vulnerable rather than aggressive emotions that lead to a need for connection with the spouse. In this case, when couples are emotionally involved with each other, conflict can mitigate; consequently, new patterns of interaction can develop, which may explain the effectiveness of EFCT, compared to ACT (Fauchier \& Margolin, 2004). This result is in line with Akhavan Bitaghsir et al.'s study which indicates EFCT is more effective than ACT on marital adjustment and marital satisfaction (Akhavan Bitaghsir, Sanaee Zaker, Navabinejad \& Farzad, 2017).

The obtained results corroborated the effectiveness of EFCT and ACT on CERSs; however, there no study examined the effect of ACT and EFCT on CERSs in couples. However, few studies generally measured the effectiveness of ACT and EFCT on CERSs; the present study findings were consistent with those of previous re- search, such as Karaminezhad, Sodani \& Mehrabizadeh Honarmand (2017), Binandeh, Seraj Khorami, Asgari, Feizi \& Tahani (2020), Sheibani, Aerab Sheibani, Nezhad Amreei \& Javedani Masrour (2019), as well as Hamid, Boolaghi \& Kiani Moghadam (2018).

Additionally, the obtained results presented that EFCT was more effective than ACT on CERS in the explored subjects. Accordingly, the purpose of CERS is to change one's attention to or one's appraisals of a condition to alter an emotion's duration, severity, or both (Ochsner \& Gross, 2005). Moreover, in EFCT, couples' emotional processing was conducted to raise 3 main processes, as follows: retrieving and improving underdeveloped emotional responses, i.e., arrested in an earlier period and did not grow or mature; the application of the inborn adaptive potential in emotion by relating it to cognition; and the regulation of emotions when they suppress meaning creation and can no longer be linked to cognition. In other words, 3 processes were focused on the EFCT approach, including emotion development, emotion utilization, and emotion regulation (Greenberg \& Goldman, 2019). In EFCT, earlier denied emotions, when aroused in therapy, can be applied to retrieve undesired self-experience that supplies the individual information about needs satisfied or not satisfied and gives information about one's response to conditions as well as action tendencies to cope with them. Activating new emotions in therapy may support reform archaic emotional responses and change previously denied feelings from the past. Activating such denied feelings in the session makes them responsive to development. This is achieved by fusing new experiences to the past situation, produced in the present. This novel experience aids in modifying cou- 
ples' memory-based problematic emotional states applying a process of memory reconsolidation (Lane, Ryan, Nadel \& Greenberg, 2015). Consequently, this helps subjects adjust their interactions with their surroundings and may be a reason for the effectiveness of EFCT, compared to ACT (Greenberg \& Goldman, 2019).

\section{Conclusion}

Based on the present study findings, EFCT and ACT reduced marital conflict and enhanced CERS in the explored married women. Moreover, the obtained results signified that EFCT was more effective than ACT in improving marital conflict and CERS in the study subjects. Applying EFCT, as the main and first-choice treatment, can help improve marital conflict and CERS in this population.

This study had some limitations. First, the sample was inadequately diverse; thus, it may hamper the generalizability of the findings. Furthermore, the study subjects were restricted to women referring to Tehran's clinics. Future research in this domain may wish to replicate in the other clinics of Tehran or even other cities with more diverse populations and considering both couples. Another study limitation was the inadequacy of control on intruding variables, such as socioeconomic status and income level of the study sample. Future studies are suggested to consider these intruding variables.

\section{Ethical Considerations}

\section{Compliance with ethical guidelines}

The relevant ethical approval was acquired from the Ethics Committee for Research at Mazandaran University of Medical Sciences (Code: IR.MAZUMS. REC.1396.2695).

\section{Funding}

This research did not receive any grant from funding agencies in the public, commercial, or non-profit sectors.

\section{Authors' contributions}

Conceptualization and Supervision: Shahrbanoo Ghahari and Leili Jamil; Methodology: Shahrbanoo Ghahari; Investigation, Writing - original draft, and Writing - review \& editing: All authors; Data collection: Shahrbanoo Ghahari, Leili Jamil, and Nazanin Farrokhi; Data analysis: Shahrbanoo Ghahari and Reza Davoodi.
The authors declared no conflicts of interest.

\section{Acknowledgments}

The authors would like to thank the management and staff of Tehran Psychiatric Institute for their contribution to this research. This work would not have been possible without their support.

\section{References}

Ahmadzadeh, L., Vaezi, M., Sodagar, Sh., \& Golmohammad Nazhad, Gh. R. (2019). The effect of acceptance and commitment therapy adopted for couples compared with integrative couple therapy on marital conflicts of couples with breast cancer. Iranian Journal of Breast Disease, 12(3), 47-59. [DOI:10.30699/acadpub.ijbd.12.3.47]

Akhavan Bitaghsir, Z., Sanaee Zaker, B., Navabinejad, Sh., \& Farzad, V. A. (2017). [Comparetive of emotional focused couple therapy and acceptance and commitment therapy on marital adjustment and marital satisfaction (Persian)]. Iranian Journal of Health Education and Health Promotion, 5(2), 121-8. [DOI:10.30699/acadpub.ijhehp.5.2.121]

Aldao, A., \& Nolen-Hoeksema, S. (2012). The influence of context on the implementation of adaptive emotion regulation strategies. Behaviour Research and Therapy, 50(7-8), 493-501. [DOI:10.1016/j.brat.2012.04.004] [PMID]

Amani, A., Isanejad, O., \& Alipour, E. (2018). [Effectiveness of acceptance and commitment group therapy on marital distress, marital conflict and optimism in married women visited the counseling center of Imam Khomeini Relief Foundation in Kermanshah (Persian)]. Shenakht Journal of Psychology \& Psychiatry, 5(1), 42-64. [DOI:10.29252/shenakht.5.1.42]

Amato, P. R., \& Hohmann-Marriott, B. (2007). A comparison of high-and low-distress marriages that end in divorce. Journal of Marriage and Family, 69(3), 621-38. [DOI:10.1111/j.17413737.2007.00396.x]

Arabnejad, S., Birashk, B., \& Abolmaali Alhosseini, KH. (2014). [The effectiveness of Acceptance and Commitment Therapy (ACT) on increasing Marital Intimacy and decreasing Marital Conflicts between the couples of Tehran (Persian)]. Journal of Social Issues E Humanities, 2(8), 89-93.

Bakhtiari, M. (2000). [The study in psychiatric disorder in patients with body dysmorphic disorder (Persian)]. Tehran: Iran University of Medical Sciences.

Balzarotti, S., Biassoni, F., Villani, D., Prunas, A., \& Velotti, P. (2016). Individual differences in cognitive emotion regulation: Implications for subjective and psychological well-being. Journal of Happiness Studies, 17(1), 125-43. [DOI:10.1007/ s10902-014-9587-3]

\section{Conflict of interest}


Barati-Bagherabad, T. (1996). Effects of marital conflict on husband and wife interrelationship [MSc. thesis]. Islamic Azad University of Rudehen, Tehran, Iran.

Beasley, C. C., \& Ager, R. (2019). Emotionally focused couples therapy: A systematic review of its effectiveness over the past 19 years. Journal of Evidence-Based Social Work, 16(2), 144-59. [D OI:10.1080/23761407.2018.1563013] [PMID]

Ben-Naim, S., Hirschberger, G., Ein-Dor, T., \& Mikulincer, M. (2013). An experimental study of emotion regulation during relationship conflict interactions: The moderating role of attachment orientations. Emotion, 13(3), 506-19. [DOI:10.1037/ a0031473] [PMID]

Binandeh, E. S., Seraj Khorami, N., Asgari, P., Feizi, G., \& Tahani, B. (2020). [The effectiveness of acceptance and commitment therapy on cognitive emotion regulation and symptoms severity in dental anxiety patients (Persian)]. Journal of Research in Behavioural Sciences, 17(4), 629-41. http://rbs.mui. ac.ir/article-1-711-en.html

Birditt, K. S., Brown, E., Orbuch, T. L., \& Mcllvane, J. M. (2010). Marital conflict behaviors and implications for divorce over 16 years. Journal of Marriage and Family, 72(5), 1188-204. [DOI:10.1111/j.1741-3737.2010.00758.x] [PMID] [PMCID]

Birditt, K. S., Wan, W. H., Orbuch, T. L., \& Antonucci, T. C. (2017). The development of marital tension: Implications for divorce among married couples. Developmental Psychology, 53(10), 1995-2006. [DOI:10.1037/dev0000379] [PMID] [PMCID]

Bloch, L., Haase, C. M., \& Levenson, R. W. (2014). Emotion regulation predicts marital satisfaction: More than a wives' tale. Emotion, 14(1), 130-44. [DOI:10.1037/a0034272] [PMID] [PMCID]

Braithwaite, S. R., Delevi, R., \& Fincham, F. D. (2010). Romantic relationships and the physical and mental health of college students. Personal Relationships, 17(1), 1-12. [DOI:10.1111/ j.1475-6811.2010.01248.x]

Curșeu, P. L., Boros, S., \&Oerlemans, L. A.G. (2012). Taskand relationship conflict in short-term and long-term groups: The critical role of emotion regulation. International Journal of Conflict Management, 23(1), 97-107. [DOI:10.1108/10444061211199331]

Delatorre, M. Z., \& Wagner, A. (2018). Marital conflict management of married men and women. Psico-USF, 23(2), 229-40. [DOI:10.1590/1413-82712018230204]

Farahanifar, M., Heidari, H., Davodi, H., \& Aleyasin, S. A. (2019) The effect of acceptance and commitment therapy on the conflict resolution styles of incompatible marital women. International Archives of Health Sciences, 6(2), 101-7. [DOI:10.4103/ iahs.iahs_8_19]

Fauchier, A., \& Margolin, G. (2004). Affection and conflict in marital and parent-child relationships. Journal of Marital and Family Therapy, 30(2), 197-211. [DOI:10.1111/j.1752-0606.2004. tb01234.x] [PMID]

Finkel, E. J., Slotter, E. B., Luchies, L. B., Walton, G. M., \& Gross, J. J. (2013). A brief intervention to promote conflict reappraisal preserves marital quality over time. Psychological Science, 24(8), 1595-601. [DOI:10.1177/0956797612474938] [PMID]
Garnefski, N., Baan, N., \& Kraaij, V. (2005). Psychological distress and cognitive emotion regulation strategies among farmers who fell victim to the foot-and-mouth crisis. Personality and Individual Differences, 38(6), 1317-27. [DOI:10.1016/j. paid.2004.08.014]

Garnefski, N., \& Kraaij, V. (2006). Cognitive emotion regulation questionnaire-development of a short 18-item version (CERQ-short). Personality and Individual Differences, 41(6), 1045-53. [DOI:10.1016/j.paid.2006.04.010]

Geiss, S. K., \& Daniel O'Leary, K. (1981). Therapist ratings of frequency and severity of marital problems: Implications for research. Journal of Marital and Family Therapy, 7(4), 515-20. [DOI:10.1111/j.1752-0606.1981.tb01407.x]

Girard, A., \& Woolley, S. R. (2017). Using emotionally focused therapy to treat sexual desire discrepancy in couples. Journal of Sex \& Marital Therapy, 43(8), 720-35. [DOI:10.1080/009262 3X.2016.1263703] [PMID]

Gottman, J. M. (2014). What predicts divorce?: The relationship between marital processes and marital outcomes. Hove: Psychology Press. https://books.google.com/ books?id=ziABAwAAQBAJ\&dq

Greenberg, L. S., \& Goldman, R. (2007). Case formulation in emotion-focused therapy. In T. D. Eells (Ed.), Handbook of psychotherapy case formulation (pp. 379-411). $2^{\text {nd }} \mathrm{Ed}$ New York: Guilford Press. https://books.google.com/ books?id=xdKC2rflrxIC\&dq

Greenberg, L. S., \& Goldman, R. N., Eds. (2019). Clinical handbook of emotion-focused therapy. Washington, D.C.: American Psychological Association. [DOI:10.1037/0000112-000]

Greenberg, L. S., \& Johnson, S. M. (1988). Emotionally focused therapy for couples. New York: Guilford Press. https:/ / books. google.com/books?id=54B5OHg8ZvUC\&dq

Greenman, P. S., \& Johnson, S. M. (2013). Process research on Emotionally Focused Therapy (EFT) for couples: Linking theory to practice. Family Process, 52(1), 46-61. [DOI:10.1111/ famp.12015] [PMID]

Gross, J. J. (2001). Emotion regulation in adulthood: Timing is everything. Current Directions in Psychological Science, 10(6), 214-9. [DOI:10.1111/1467-8721.00152]

Gurman, A. S., Lebow, J. L., \& Snyder, D. K., Eds. (2015). Clinical handbook of couple therapy. New York: Guilford Press. https:// books.google.com/books?id=XBnvCQAAQBAJ\&dq

Hahlweg, K., \& Richter, D. (2010). Prevention of marital instability and distress. Results of an 11-year longitudinal follow-up study. Behaviour Research and Therapy, 48(5), 377-83. [DOI:10.1016/j.brat.2009.12.010] [PMID]

Hamid, N., Boolaghi, Y., \& Kiani Moghadam, A. S. (2018). The efficacy of acceptance and commitment based therapy (ACT) on depressive symptoms and cognitive emotion regulation strategies in depressive students. International Journal of Psychology, 12(1), 5-29. [DOI:10.24200/ijpb.2018.58144]

Hasani, J. (2011). [The reliability and validity of the short form of the cognitive emotion regulation questionnaire (Persian)]. Journal of Research in Behavioural Sciences, 9(4), 229-40. http:/ / rbs.mui.ac.ir/article-1-207-fa.html

Havaasi, N., Zahra Kaar, K., \& Mohsen Zadeh, F. (2018). Compare the efficacy of emotion focused couple therapy and Gott- 
man couple therapy method in marital burnout and changing conflict resolution styles. Journal of Fundamentals of Mental Health, 20(1), 15-25. [DOI:10.22038/JFMH.2017.10034]

Hayes, S. C., \& Strosahl, K. D., Eds. (2013). A practical guide to acceptance and commitment therapy. New York: Springer Science \& Business Media. https://books.google.com/ books?id=OJJyBgAAQBAJ\&dq

Herzberg, P. Y. (2013). Coping in relationships: The interplay between individual and dyadic coping and their effects on relationship satisfaction. Anxiety, Stress \& Coping, 26(2), 136-53. [DOI:10.1080/10615806.2012.655726] [PMID]

John, O. P., \& Gross, J. J. (2004). Healthy and unhealthy emotion regulation: Personality processes, individual differences, and life span development. Journal of Personality, 72(6), 1301-34. [DOI:10.1111/j.1467-6494.2004.00298.x] [PMID]

Johnson, S. M., \& Denton, W. (2002). Emotionally focused couple therapy: Creating secure connections. In A. S. Gurman, \& N. S. Jacobson (Eds.), Clinical handbook of couple therapy (pp. 221-250). New York: The Guilford Press. https://psycnet. apa.org/record/2003-04270-008

Johnson, S. M., Hunsley, J., Greenberg, L., \& Schindler, D. (1999). Emotionally focused couples therapy: Status and challenges. Clinical Psychology: Science and Practice, 6(1), 67-79. [DOI:10.1093/clipsy.6.1.67]

Karaminezhad, Z., Sodani, M., \& Mehrabizadeh Honarmand, M. (2017). [Effectiveness emotion focused therapy approach on cognitive emotion regulation on emotional breakdown girl students (Persian)]. Yafteh, 18(4), 79-86. http:/ / yafte.lums. ac.ir/article-1-2416-en.html

Kavousian, J., Haniffi, H., \& Karimi, K. (2017). [The efficacy of Acceptance and Commitment Therapy (ACT) on marital satisfaction in couples (Persian)]. Journal of Health \& Care, 19(1), 75-87. http:/ /hcjournal.arums.ac.ir/article-1-706-en.html

Kiecolt-Glaser, J. K., Bane, C., Glaser, R., \& Malarkey, W. B. (2003). Love, marriage, and divorce: Newlyweds' stress hormones foreshadow relationship changes. Journal of Consulting and Clinical Psychology, 71(1), 176-88. [DOI:10.1037/0022006X.71.1.176] [PMID]

Kirkpatrick, L. A., \& Davis, K. E. (1994). Attachment style, gender, and relationship stability: A longitudinal analysis. Journal of Personality and Social Psychology, 66(3), 502-12. [DOI:10.1037/0022-3514.66.3.502] [PMID]

Khanei, D., Jazayeri, R. S., Bahrami, F., Montazeri, N., \& Etemadi, O. (2018). Investigating the effectiveness of Acceptance and Commitment Therapy (ACT) on marital conflicts of coronary artery bypass patients. Clinical Psychology Studies, 9(33), 91-103. [DOI:10.22054/JCPS.2019.36697.2012]

Khanjani Veshki, S., Shafiabady, A., Farzad, V., \& Fatehizade, M. (2016). A comparison of the effectiveness of cognitive-behavioral couple therapy and acceptance and commitment couple therapy in the couple's conflict in the city of Isfahan. Jundishapur Journal of Health Sciences, 9(3), e43085. [DOI:10.5812/ jjhs.43085]

Klein, S. R., Renshaw, K. D., \& Curby, T. W. (2016). Emotion regulation and perceptions of hostile and constructive criticism in romantic relationships. Behavior Therapy, 47(2), 143-54. [DOI:10.1016/j.beth.2015.10.007] [PMID]
Lane, R. D., Ryan, L., Nadel, L., \& Greenberg, L. (2015). Memory reconsolidation, emotional arousal, and the process of change in psychotherapy: New insights from brain science. Behavioral and Brain Sciences, 38, e1. [DOI:10.1017/S0140525X14000041] [PMID]

Levenson, R. W., Haase, C. M., Bloch, L., Holley, S. R., \& Seider, B. H. (2013). Emotion regulation in couples. In J. J. Gross (Ed.), Handbook of emotion regulation (pp. 187-202). $2^{\text {nd }}$ Ed. New York: Guilford Press. https://books.google.com/ books?id=hcgBAgAAQBAJ\&dq

Lindahl, K. M., \& Malik, N. M. (2011). Marital conflict typology and children's appraisals: The moderating role of family cohesion. Journal of Family Psychology, 25(2), 194-201. [DOI:10.1037/a0022888] [PMID]

Litzinger, S., \& Gordon, K. C. (2005). Exploring relationships among communication, sexual satisfaction, and marital satisfaction. Journal of Sex E Marital Therapy, 31(5), 409-24. [DOI:10.1080/00926230591006719] [PMID]

Maffei, C., Fossati, A., Agostoni, I., Barraco, A., Bagnato, M., \& Deborah, D., et al. (1997). Interrater reliability and internal consistency of the structured clinical interview for DSM-IV axis II personality disorders (SCID-II), version 2.0. Journal of Personality Disorders, 11(3), 279-84. [DOI:10.1521/ pedi.1997.11.3.279] [PMID]

Markman, H. J., \& Hahlweg, K. (1993). The prediction and prevention of marital distress: An international perspective. Clinical Psychology Review, 13(1), 29-43. [DOI:10.1016/02727358(93)90006-8]

Markman, H. J., Rhoades, G. K., Stanley, S. M., Ragan, E. P., \& Whitton, S. W. (2010). The premarital communication roots of marital distress and divorce: The first five years of marriage. Journal of Family Psychology, 24(3), 289-98. [DOI:10.1037/ a0019481] [PMID] [PMCID]

McNulty, J. K., \& Hellmuth, J. C. (2008). Emotion regulation and intimate partner violence in newlyweds. Journal of Family Psychology, 22(5), 794-7. [DOI:10.1037/a0013516] [PMID]

McRae, K. (2016). Cognitive emotion regulation: A review of theory and scientific findings. Current Opinion in Behavioral Sciences, 10, 119-24. [DOI:10.1016/j.cobeha.2016.06.004]

Mikulincer, M., \& Shaver, P. R. (2010). Attachment in adulthood: Structure, dynamics, and change. New York: Guilford Press. https:/ / books.google.com/books?id=5egODAAAQBAJ\&dq

Miller, R. B., Hollist, C. S., Olsen, J., \& Law, D. (2013). Marital quality and health over 20 years: A growth curve analysis. Journal of Marriage and Family, 75(3), 667-80. [DOI:10.1111/ jomf.12025]

Naghdi, H., Hatami, M., Kayamanesh, A. R., \& Navobinejad, Sh. (2017). [The comparison of the effect of emotion focused couple therapy and the problem-centered systemic therapy on marital conflict of spouses of the men under treatment of substance dependence (Persian)]. Family Counseling and Psychotherapy, 7(1), 23-44. https:/ / fcp.uok.ac.ir/article_48681.html

Najafi, M., Soleimani, A. A., Ahmadi, Kh., Javidi, N., \& Hoseini Kamkar, E. (2015). The effectiveness of emotionally focused therapy on enhancing marital adjustment and quality of life among infertile couples with marital conflicts. International Journal of Fertility \& Sterility, 9(2), 238-46. [DOI:10.22074/ ijfs.2015.4245] [PMID] [PMCID] 
Ochsner, K. N., \& Gross, J. J. (2005). The cognitive control of emotion. Trends in Cognitive Sciences, 9(5), 242-9. [DOI:10.1016/j. tics.2005.03.010] [PMID]

Peterson, B. D., Eifert, G. H., Feingold, T., \& Davidson, S. (2009) Using acceptance and commitment therapy to treat distressed couples: A case study with two couples. Cognitive and Behavioral Practice, 16(4), 430-42. [DOI:10.1016/j.cbpra.2008.12.009]

Priest, J. B. (2013). Emotionally focused therapy as treatment for couples with generalized anxiety disorder and relationship distress. Journal of Couple \& Relationship Therapy, 12(1), 22-37. [DOI:10.1080/15332691.2013.749763]

Qadar, F. (2016). Self-talk: Effects on emotion in interpersonal communication context [MA. thesis]. Tucson, AZ: The University of Arizona. https://repository.arizona.edu/handle/10150/613581

Rostami, M., Taheri, A., Abdi, M., \& Kermani, N. (2014). The effectiveness of instructing emotion-focused approach in improving the marital satisfaction in couples. ProcediaSocial and Behavioral Sciences, 114, 693-8. [DOI:10.1016/j.sbspro.2013.12.769]

Shamsipour, H., Norouzi Kouhdasht, R., Mohammadi, H., Azari, E., \& Norouzi, M. (2018). [The effect of emotion-focused couple therapy based on religious teachings on social compatibility and marital conflicts (Persian)]. Journal of Pizhūhish dar din va Salāmat, 4(4), 44-58. https://journals.sbmu.ac.ir/enjrrh/article/view/22953

Sheibani, H., Aerab Sheibani, Kh., Nezhad Amreei, N., \& Javedani Masrour, M. (2019). An investigation of the effects of the acceptance and commitment therapy in groups on the cognitive strategies of emotion regulation and self-control in coronary heart disease patients. Journal of Medicine and Life, 12(4), 361-7. [PMID] [PMCID]

Snyder, D. K., Castellani, A. M., \& Whisman, M. A. (2006) Current status and future directions in couple therapy. Annual Review of Psychology, 57, 317-44. [DOI:10.1146/annurev. psych.56.091103.070154] [PMID]

Soleimani, A. A., Najafi, M., Ahmadi, K., Javidi, N., Kamkar, E. H., \& Mahboubi, M. (2015). The effectiveness of emotionally focused couples therapy on sexual satisfaction and marital adjustment of infertile couples with marital conflicts. International Journal of Fertility \& Sterility, 9(3), 393-402. [DOI:10.22074/ ijfs.2015.4556] [PMID] [PMCID]

Solymani Ahmadi, F., Zarei, E., \& Fallahchai, S. R. (2014). The effectiveness of emotionally-focused couple therapy in resolution of marital conflicts between the couples who visited the consultation centers. Journal of Educational and Management Studies, 4(1), 118-23. http://www.jems.science-line.com/attachments/article/21/J.\%20Educ.\%20Manage.\%20Stud.,\%20 4(1)\%20118-123\%202014.pdf

SPSS, I. (2015). IBM SPSS statistics for windows, version 23.0 Armonk: IBM Corp. https://www.ibm.com/support/pages/ibmsearch?q=IBM \%20SPSS\%20Statistics \%20for\%20Windows, $\% 20$ Version $\% 2023.0$

Strong, B., DeVault, C., \& Cohen, T. F. (2010). The marriage and family experience: Intimate relationships in a changing society (11 ${ }^{\text {th }}$ ed.). California: Cengage Learning. https://www. google.com/books/edition/The_Marriage_and_Family_Experience_Intim/MX0JzgEACAAJ?hl=en
Tolorunleke, C. A. (2014). Causes of marital conflicts amongst couples in Nigeria: Implication for counselling psychologists. Procedia - Social and Behavioral Sciences, 140, 21-6. [DOI:10.1016/j.sbspro.2014.04.381]

Treboux, D., Crowell, J. A., \& Waters, E. (2004). When "new" meets "old": Configurations of adult attachment representations and their implications for marital functioning. Developmental Psychology, 40(2), 295-314. [DOI:10.1037/00121649.40.2.295] [PMID]

Vanhee, G., Lemmens, G. M. D., Moors, A., Hinnekens, C., \& Verhofstadt, L. L. (2018). EFT-C's understanding of couple distress: An overview of evidence from couple and emotion research. Journal of Family Therapy, 40(S1), S24-44. [DOI:10.1111/1467-6427.12128]

Vater, A., \& Schröder-Abé, M. (2015). Explaining the link between personality and relationship satisfaction: Emotion regulation and interpersonal behaviour in conflict discussions. European Journal of Personality, 29(2), 201-15. [DOI:10.1002/ per.1993]

Whisman, M. A., Dixon, A. E., \& Johnson, B. (1997). Therapists' perspectives of couple problems and treatment issues in couple therapy. Journal of Family Psychology, 11(3), 361-6. [DOI:10.1037/0893-3200.11.3.361]

Wiebe, S. A., \& Johnson, S. M. (2016). A review of the research in emotionally focused therapy for couples. Family Process, 55(3) 390-407. [DOI:10.1111/famp.12229] [PMID]

Woldarsky Meneses, C. (2017). Emotion-focused couples therapy. Person-Centered \& Experiential Psychotherapies, 16(3), 23655. [DOI:10.1080/14779757.2017.1330706] 
This Page Intentionally Left Blank 